\title{
Clinicopathological profile of uterine fibroid at a medical college hospital
}

\author{
Kaushal A. ${ }^{1}$, Das Gupta D. ${ }^{2 *}$, Kumar A. ${ }^{3}$ \\ DOI: https://doi.org/10.17511/jopm.2020.i02.07 \\ 1 Anjani Kaushal, Assistant Professor, Department of Pathology, Mata Gujari Memorial Medical College and Lions Seva Kendra Hospital, \\ Kishanganj, Bihar, India. \\ 2* Debi Prosad Das Gupta, Associate Professor, Department of Pathology, Mata Gujari Memorial Medical College and Lions Seva Kendra \\ Hospital, Kishanganj, Bihar, India. \\ 3 Ajay Kumar, Associate Professor, Department of Pathology, Mata Gujari Memorial Medical College and Lions Seva Kendra Hospital, \\ Kishanganj, Bihar, India.
}

Introduction: Leiomyomas are usually asymptomatic. Symptoms may be seen depending on their size, location and hormonal effects. It is the most common uterine tumour seen in gynaecological practice. Knowledge of clinical features and histopathological changes are helpful. Methods: The present cross-sectional study included 109 cases of uterine fibroid. Clinical details and findings of histopathological examination were noted. Results: Most of the patients belonged to the age group of 50-60 years. Menstrual irregularities were seen in $71.6 \%$ of cases. $39.4 \%$ suffered from abdominal pain and infertility was seen in $11.9 \%$ cases. In $70.6 \%$ of cases, proliferative endometrium was found. Secretory endometrium was seen in $13.8 \%$ and atrophic in $10.1 \%$. Most of the cases had intramural fibroid (58.7\%). Conclusion: Hyaline degeneration, myxoid degeneration and cystic degeneration are the commonly seen secondary changes. Proper diagnosis and timely management are essential for the management of these tumours.

Keywords: Observational study, Pathological changes, Uterine fibroid

\section{Corresponding Author}

Debi Prosad Das Gupta, Associate Professor, Department of Pathology, Mata Gujari Memorial Medical College and Lions Seva Kendra Hospital, Kishanganj, Bihar, India.

Email: debiprasad57@yahoo.com

\section{How to Cite this Article}

Kaushal A, Gupta DPD, Kumar A, Clinicopathological profile of uterine fibroid at a medical college hospital. Trop J Pathol Microbiol. 2020;6(2):155-160. Available From

https://pathology.medresearch.in/index.php/jopm/ar ticle/view/436
To Browse

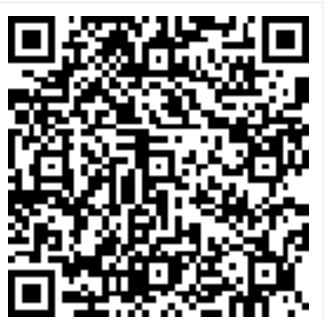

\section{Introduction}

Uterine fibroids are one of the common benign tumours of uterus seen in women of reproductive age group. These constitute 5$10 \%$ of all these tumours [1].

These are also known as uterine leiomyomata,
Uterine leiomyomas or uterine myomas and are benign growth of uterine smooth muscles which are accompanied by connective tissue.

Their predominant occurrence in the reproductive age group is associated with concurrent expression of higher levels of oestrogen receptors and they tend to shrink
Manuscript Received 10-01-2020

Conflict of Interest No

Review Round 1
20-01-2020
Funding
Nil

$\mathrm{Nil}$

Review Round 2
$28-01-2020$
$\begin{gathered}\text { Ethical Approval } \\ \text { Yes }\end{gathered}$

Review Round 2

Yes
Review Round 3

Plagiarism X-checker $18 \%$
Accepted 01-02-2020

Note 
During hypoestrogenic states such as after menopause $[2,3]$.

They have been classified according to their location as intramural, subserosal, submucosal and cervical. Intramural fibroids are commonest and are located within the wall of the uterus. Subserosal fibroids are located underneath the mucosal surface of the uterus. Submucosal fibroids are located in the muscle beneath the endometrium of the uterus and tend to distort the uterine cavity. Cervical fibroids are located in the wall of the cervix [4].

Leiomyomas are usually asymptomatic. Symptoms may be seen depending on their size, location and hormonal effects. Menorrhagia is the commonest clinical manifestations. Other symptoms are dysmenorrhoea, pain and feeling of a mass in the abdomen. It can also lead to infertility and sexual dysfunction [5].

Symptomatic leiomyomas are treated by myomectomy in younger women desirous of retaining the childbearing function. Hysterectomy is done in those who have completed family [6].

The clinical and pathological features vary from place to place and also changes with time. No such study has recently been done in this area. Hence, this study was conducted.

Aims and objectives- The present study was conducted to assess the clinical profile of patients suffering from fibroid uterus and the associated pathological changes seen in these fibroids.

\section{Material and Methods}

Study setting: The present study was conducted at the Department of Pathology, MGMMCH, Kishanganj, Bihar. It is a tertiary care institute in Kishanganj district of Bihar which shares a border with West Bengal and Nepal. Patients from the neighbouring districts of Bihar, West Bengal and Tarai region of Nepal visit this place.

Duration and type of study: The present study was conducted between February 2018 to July 2019.

Study subjects: Patients reporting to OPD or emergency of Gynaecology department of the institute and found to be suffering from leiomyoma of the uterus were included.

Inclusion criteria: Patients above 18 years of age suffering from leiomyoma of the uterus and treated
In myomectomy or hysterectomy was performed were included in the present study.

Exclusion criteria: Cases who were seriously ill, who did not give consent or in which biopsy specimen could not be processed properly were excluded.

Sampling: All the patients reporting during the study period and fulfilling selection criteria were included in the present study. A total of 109 cases were included.

Data collection procedure: The patients were visited in the wards. Detailed clinical history was taken. Data regarding age, reproductive status, history, clinical diagnosis and details of surgical procedure were recorded.

The excised surgical specimen was received in the Department of Pathology and was fixed in $10 \%$ neutral buffered formalin for 24-48 hours. Gross examination of the uterus, cervix with or without bilateral adnexae was done to note the overall appearance. A minimum of two sections from the representative sites was taken. These were processed and paraffin-embedded.

The sections were prepared and stained with hematoxylin-eosin ( $\mathrm{H}$ and $\mathrm{E})$. A detailed histopathological examination was done to assess glandular and stromal changes, secondary changes in leiomyoma and additional findings in fallopian tubes and ovaries. The findings were noted in pretested semi-structured proforma.

Data analysis: Data was entered in Microsoft Excel 2010. Data analysis was done using Statistical Package for Social Sciences (SPSS) v 16.0. Data were summarized as frequency and percentage for categorical variables and mean and SD for numerical variables. Statistical tests were done as needed. the $p$-value of $<0.05$ was considered to be statistically significant.

Ethical consideration and permission: Approval from the Institutional Ethics Committee was obtained. The study participants were informed about the importance and informed consent was taken. Confidentiality of records was maintained.

\section{Results}

The present study included 109 cases of uterine fibroid. Table-1 shows the age distribution of patients. Most of the patients belonged to the age group of 50-60 years. 
Table-1: Age of the patients

\begin{tabular}{|l|l|l|}
\hline \multicolumn{1}{|c|}{ Age (in years) } & Frequency & Percentage (\%) \\
\hline$<40$ & 7 & 6.4 \\
\hline $40-50$ & 46 & 42.2 \\
\hline $50-60$ & 49 & 45 \\
\hline$>60$ & 8 & 7.3 \\
\hline
\end{tabular}

Table-2 shows clinical manifestations seen in cases with uterine fibroid. Menstrual irregularities were seen in $71.6 \%$ of cases.

$39.4 \%$ suffered from abdominal pain and infertility was seen in $11.9 \%$ cases.

Table-2: Clinical manifestations

\begin{tabular}{|l|l|l|}
\hline \multicolumn{1}{|c|}{ Clinical manifestations } & Frequency & Percentage (\%) \\
\hline Menstrual irregularity & 78 & 71.6 \\
\hline Dysmenorrhoea & 20 & 18.3 \\
\hline Pain abdomen & 43 & 39.4 \\
\hline Urinary symptoms & 17 & 15.6 \\
\hline Infertility & 13 & 11.9 \\
\hline Others & 10 & 9.2 \\
\hline
\end{tabular}

Table-3 shows endometrial changes during the histopathological examination. In $70.6 \%$ of cases, proliferative endometrium was found.

Secretory endometrium was seen in $13.8 \%$ and atrophic in $10.1 \%$.

Table-3: Endometrial changes seen

\begin{tabular}{|l|l|l|}
\hline \multicolumn{1}{|c|}{ Endometrial changes } & Frequency & Percentage (\%) \\
\hline Proliferative & 77 & 70.6 \\
\hline secretory & 15 & 13.8 \\
\hline Atrophic & 11 & 10.1 \\
\hline Hyperplastic & 4 & 3.7 \\
\hline Cystic glandular hyperplasia & 1 & 0.9 \\
\hline
\end{tabular}

Table-4 shows complications in the uterine fibroid.

Chronic cervicitis was present in $77.1 \%$ of cases. $18.3 \%$ of cases had cystic ovaries and $9.2 \%$ had adenomyosis.

\section{Table-4: Complications of uterine fibroid}

\begin{tabular}{|l|l|l|}
\hline \multicolumn{1}{|c|}{ Complications* } & Frequency & \multicolumn{1}{c|}{ Percentage (\%) } \\
\hline Chronic cervicitis & 84 & 77.1 \\
\hline Cystic ovaries & 20 & 18.3 \\
\hline Adenomyosis & 10 & 9.2 \\
\hline PID & 2 & 1.8 \\
\hline
\end{tabular}

*- multiple responses

Table-5 shows the location of the fibroid. Most of the cases had intramural fibroid (58.7\%). It was subserosal in $19.3 \%$ cases and submucosal in $4.6 \%$.
Table-5: Location of fibroid

\begin{tabular}{|l|l|l|}
\hline \multicolumn{1}{|c|}{ Location of fibroid } & Frequency & \multicolumn{1}{c|}{ Percentage (\%) } \\
\hline Intramural & 64 & 58.7 \\
\hline Subserosal & 21 & 19.3 \\
\hline Adenomyosis & 19 & 17.4 \\
\hline Submucosal & 5 & 4.6 \\
\hline
\end{tabular}

Table-6 shows degenerations seen in fibroid upon histopathological examination. Hyaline degeneration was seen in $20.2 \%$ cases, cystic degeneration in $4.6 \%$ and myxoid degeneration in $3.7 \%$. $67.9 \%$ of cases did not show any degeneration.

Table-6: Degenerations seen in fibroid

\begin{tabular}{|l|l|l|}
\hline \multicolumn{1}{|c|}{ Degenerations seen } & Frequency & Percentage (\%) \\
\hline Hyaline & 22 & 20.2 \\
\hline Myxoid & 4 & 3.7 \\
\hline Cystic & 5 & 4.6 \\
\hline Red & 1 & 0.9 \\
\hline Calcification & 2 & 1.8 \\
\hline None & 74 & 67.9 \\
\hline
\end{tabular}

\section{Discussion}

Uterine fibroid is the commonest tumour of the uterus. It is also known as leiomyoma or uterine myoma and consists of smooth muscles cells mixed with the connective tissue of the uterus. These tumours may be single or can occur as diffuse or multiple tumours. A most common site is fundus and uterine body. Cervical leiomyomas are rare [7].

Pathophysiology of leiomyomas indicates that these tumours occur due to overgrowth of smooth muscle cells along with connective tissue. The monoclonal proliferation of smooth muscle cells is seen. It has been seen that these tumours are associated with increased oestrogen and progesterone receptors.

The proliferation of fibroid is associated with increased levels of oestrogen and is commonly seen in the reproductive period. A decrease in oestrogen levels is associated with regression of these tumours as is found during treatment of $\mathrm{GnRH}$ agonist therapy or during menopause [8].

They present with a wide spectrum of clinical symptoms which are related to pressure due to these tumours or due to menstrual irregularity. Pressure symptoms include backache, pain abdomen, frequency of urination, tinismus, the heaviness of abdomen and bloating. Menstrual irregularities include menorrhagia and dysmenorrhoea. In severe cases, infertility is also seen. Large fibroids may cause miscarriage, $\mathrm{APH}$, 
Foetal malposition and preterm labour during pregnancy[9].

Grossly, the uterine fibroids present as wellcircumscribed, firm, grey-white bulging lesions. These can be easily separated from the myometrium. On microscopic examination, the cut surface shows whorled appearance with cells arranged in crisscrossing fascicles. They are associated with secondary changes and degenerations which alters the gross appearance. Hyaline degeneration/necrosis is most common and is seen in more than $60 \%$, particularly in postmenopausal women. Cystic degeneration, fatty degeneration, myxoid change and calcification occur in $4 \%$ each. These tumours show atrophy with significant shrinkage and fibrosis after menopause. Red degeneration is due to tumour vessel thrombosis and is associated with pregnancy and contraceptive use $[10,11]$.

The present study included 109 cases of uterine fibroid. Most of the patients belonged to the age group of 50-60 years. Sushama et al found that the majority of the patients were in the age group of 41-50 years $(54.76 \%)$. Gowri et al reported that patients with leiomyomas were aged between 2 nd and 5 th decade of life. The youngest was 26 years and the oldest was 59 years. Gowri et al also found that patients with leiomyomas were aged between 2nd and 5th decade of life [1]. Lahori et al observed that the age of the patients with leiomyoma ranged from18-62 years. Majority of the patients were between $41-50$ years accounting for $46.84 \%$ cases [12]. However, Jalandhara et al found that the mean age of cases was 38.5 years [13].

Menstrual irregularities were seen in $71.6 \%$ of cases. $39.4 \%$ suffered from abdominal pain and infertility was seen in $11.9 \%$ cases. Lahori et al found that menorrhagia was the commonest symptom constituting $37.97 \%$ cases, followed by pain in abdomen in $18.99 \%$ cases and dysmenorrhea in $17.72 \%$ cases [12]. Jalandhara et al found that the most common mode of presentation was menstrual disturbances (76\%), among which menorrhagia was seen in $64 \%$ of the cases while primary infertility was seen in $15 \%$ of the patients [13].

Most of the cases had intramural fibroid (58.7\%). It was subserosal in $19.3 \%$ cases and submucosal in $4.6 \%$. Bhatta et al reported that most of the hysterectomy specimens showed single leiomyoma $(80.95 \%)$. Intramural leiomyoma was observed in
$51.2 \%$ of patients, accounting for the most common location in the uterus [14]. Gowri et al found that $48 \%$ of cases had intramural fibroid whereas subserosal (16\%) submucosal (3\%) and $33 \%$ had leiomyomas in more than one location [1]. Lahori et al also found that most common site of leiomyomas was intramural $(57.43 \%)$ followed by subserosal leiomyomas $(30.69 \%)$, submucosal leiomyomas constituted $8.91 \%$ cases while broad ligament leiomyomas constituted $2.97 \%$ cases [12]. Jalandhara et al found that intramural fibroid was the commonest variety comprising about $60 \%$ of the cases, $4 \%$ submucous, $20 \%$ subserous and adenomyosis were found in $16 \%$ of the cases [13].

Hyaline degeneration was seen in $20.2 \%$ cases, cystic degeneration in $4.6 \%$ and myxoid degeneration in $3.7 \%$. $67.9 \%$ of cases did not show any degeneration. Bhatta et al found that hyaline degeneration occurred most frequently $(7.14 \%)$ followed by calcific degeneration (1.78\%). Degeneration was not seen in the majority of the leiomyoma (89.28\%) [14]. Gowri et al reported that secondary changes occurring within leiomyomas were present in $23.6 \%$. Hyalinisation $(16.9 \%)$ was the commonest secondary degenerative change followed by cystic $(9 \%)$ and myxoid $(1.6 \%)$ change [1]. Lahori et al observed that degenerative changes were observed in $16.46 \%$ leiomyomas. Among these, $6.33 \%$ leiomyomas showed hyaline change which constituted the most common degenerative change observed, $3.8 \%$ showed a myxoid change, $3.8 \%$ showed calcification, $3.8 \%$ showed cystic and $2.53 \%$ demonstrated red degeneration [12].

In $70.6 \%$ of cases, proliferative endometrium was found. Secretory endometrium was seen in $13.8 \%$ and atrophic in $10.1 \%$. Bhatta et al also found that the most common pattern was proliferative endometrium (63.1\%). Chronic cervicitis was present in $77.1 \%$ of cases. $18.3 \%$ of cases had cystic ovaries and $9.2 \%$ had adenomyosis. Bhatta et al observed that predominant uterine pathologies associated with leiomyoma were chronic cervicitis $(58.33 \%)$ and adenomyosis (19.64\%). Malignancy associated with leiomyoma was observed in $1.8 \%$ of cases [14]. Gowri et al commented that $46.3 \%$ of endometrium showed proliferative phase and $22.8 \%$ endometrial hyperplasia. Other endometrial stromal changes were haemorrhage, chronic endometritis and tubercular endometritis [1]. Jalandhara et al reported that proliferative endometrium was noted in $96 \%$, while secretory changes were noted in $4 \%$ [13]. Histopathological examination of excised 
Fibroid is helpful in the proper evaluation of the nature of the lesion and inadequate management of the cases. Endometrial pattern and secondary changes in fibroid are crucial in the understanding of the pathology.

\section{Conclusion}

Leiomyoma is the most common uterine tumour seen in gynaecological practice. Menstrual disturbances are the commonest symptom of which menorrhagia is the most common presentation. Most of these tumours are intramural in location. The most common pattern of endometrium observed is proliferative. Hyaline degeneration, myxoid degeneration and cystic degeneration are the common secondary changes seen in fibroid uterus. Proper diagnosis and timely management are essential to avoid complications of these tumours.

Limitations of the study- The present study was descriptive in nature and only described the clinical and histopathological profile of uterine fibroids. It was collected on a small sample of 109 cases. Further study on a larger sample size can be conducted to increase the power of the study.

\section{What does the study add to the existing knowledge?}

The clinical profile of the cases of uterine fibroids in this area has been described. The common complications and histopathological changes seen have been elaborated.

\section{Author's contribution}

Dr. Anjani Kaushal: Principal author collected data and has written the manuscript.

Dr. Debi Prosad Das Gupta: Corresponding author edited the article and written the discussion.

Dr. Ajay Kumar: Did data analysis and helped in the statistical part.

\section{Reference}

01. Gowri M, Mala G, Murthy S, Nayak V. Clinicopathological study of uterine leiomyomas in hysterectomy specimens. JEMDS. 2013;2 (46)9002-9009.

doi:[Article:https://doi.org/10.14260/jemds/1563]

[Crossref]
02. Jalandhara J, Mehta K, Desai R, Parakh $P$, CHoudhary G. Clinicopathological study of uterine leiomyomas- A multicentric study in rural population. IJMHR. 2018;4(6)16-18.

[Crossref]

03. Nivethithai $P$, Nikhat $S$, Rajesh B. Uterine Fibroids- A Review. Indian J Pharm Pract. 2010;3(1)6-11.

[Crossref]

04. Dayal S, Kumar A, Verma A. Clinicopathologic Correlation of Leiomyoma With Clinical Findings and Secondary Changes in a Rural Population of North India. Am J Clin Pathol. 2014;141(2)275279.

doi:

[Article:https://doi.org/10.1309/A]CPSLMZ1TOC4]CF ][Crossref]

05. Subrata P, Srabani C, Anuradha S, Prakash PJ, Kingshuk $B$, Mrinal S. A retrospective clinicopathological study of hysterectomy cases in a tertiary care hospital in India - a review of 950 cases. Bangladesh J Med Sci. 2018;17(1)88-92. [Article:https://doi.org/10.3329/bjms.v17i1.35287] [Crossref]

06. Lahori M, Malhotra A, Sakul S, Khajuria A, Goswami K. Clinicopathological spectrum of uterine leiomyomas in a state of Northern Indiaa hospital based study. Int J Reprod Contracept Obstet Gynecol. 2016;5(7)2295-2299.

doi: [Article:https://doi.org/10.18203/23201770.ijrcog20162114][Crossref]

07. Kulkarni MR, Dutta I, Dutta DK. Clinicopathological Study of Uterine Leiomyomas- A Multicentric Study in Rural Population. J Obstet Gynecol India. 2016;66(S1)S412-S416.

[Article:https://doi.org/10.1007/s13224-015-0773-y] [Crossref]

08. Nisolle M, Gillerot S, Casanas-Roux F, Squifflet J, Berliere $M$, Donnez J. Immunohisto-chemical study of the proliferation idex, oestrogen receptor and progesterone receptors $A$ and $B$ in leiomyomata and normal myometrium during the menstrual cycle and under gonadotrophinreleasing hormone agoist therapy. Hum Reprod. 1999;14(11)2844-2850.

doi:

[Article:https://doi.org/10.1093/humrep/14.11.2844] [Crossref] 
09. Kaur H, Gulati A. Pathophysiology of fibroids. Ind J Pathol Oncol. 2014;1(1)14-17.

[Crossref]

10. Thomason P. Uterine leiomyoma. Medscape. Oct 08, 2017.

(accessed

April

9,

[Article:https://emedicine.medscape.com/article/405

676-overview][Crossref]

11. Samaila MO, Adesiyun A, Agunbiade $O$, Mohammed D. A clinicopathological assessment of hysterectomies in Zaria. Eur J Gen Med. 2009;6(3)150-153.

doi: [Article:https://doi.org/10.29333/ejgm/82660] [Crossref]
12. Bhatta S, Bhandari S, Osti BP. Histopathological study of Uterine Leiomyoma in Hysterectomy Specimens. Ann Clin Chem and Lab Med. 2018;3(2)16-20.

doi:

[Article:https://doi.org/10.3126/acclm.v3i2.20739] [Crossref]

13. Zaloudek C, Hendrickson M, Soslow R. Mesenchymal tumors of uterus. In- Blaustein Pathology of the female genital tract, 6th ed. 2011.

[Crossref] 